This is the accepted manuscript of the following publication:

De Tobel J, Ottow C, Widek T, Klasinc I, Mörnstad H, Thevissen PW, Verstraete KL. Dental and skeletal imaging in forensic age estimation: disparities in current approaches and the continuing search for optimization. Semin Musculoskelet Radiol. Accepted on December 19, 2019. 


\section{FULL TITLE PAGE}

Dental and skeletal imaging in forensic age estimation: disparities in current approaches and the continuing search for optimization

\begin{tabular}{|c|c|c|c|c|c|}
\hline $\begin{array}{l}\text { Author } \\
\text { order }\end{array}$ & First name & $\begin{array}{l}\text { Middle } \\
\text { initials }\end{array}$ & Last name & $\begin{array}{l}\text { Academic degrees } \\
\text { ORCID } \\
\text { E-mail }\end{array}$ & $\begin{array}{l}\text { Affiliat- } \\
\text { ions }\end{array}$ \\
\hline 1 & Jannick & / & De Tobel & $\begin{array}{l}\text { - Doctor of Philosophy in Health Sciences } \\
\text { (PhD) } \\
\text { - Medical doctor (MD) } \\
\text { - Doctor of Dental Medicine (DMD) } \\
\text { - Master of Science (MSc) in Forensic } \\
\text { Odontology } \\
\text { 0000-0002-8846-7339 } \\
\text { jannick.detobel@ugent.be }\end{array}$ & $a, b, c, d$ \\
\hline 2 & Christian & / & Ottow & $\begin{array}{l}\text { - Medical doctor (MD) } \\
\text { ORCID 0000-0002-0512-741X } \\
\text { christian.ottow@ukmuenster.de }\end{array}$ & $\mathrm{e}$ \\
\hline 3 & Thomas & / & Widek & $\begin{array}{l}\text { - Master of Science (MSc) in Forensic } \\
\text { Radiography } \\
\text { - Diploma in Radiography } \\
\text { 0000-0001-8474-1233 } \\
\text { thomas.widek@cfi.lbg.ac.at }\end{array}$ & $f, g, h$ \\
\hline 4 & Isabella & / & Klasinc & $\begin{array}{l}\text { - Medical doctor (MD) } \\
\text { isabella.klasinc@medunigraz.at }\end{array}$ & $\mathrm{i}$ \\
\hline 5 & Håkan & / & Mörnstad & $\begin{array}{l}\text { - Doctor of Philosophy in Health Sciences } \\
\text { (PhD) } \\
\text { - Doctor of Dental Medicine (DMD) } \\
\text { 0000-0003-1667-2568 } \\
\text { Hakan.Mornstad@forodont.se }\end{array}$ & $\bar{j}$ \\
\hline 6 & Patrick & Werner & Thevissen & $\begin{array}{l}\text { - Doctor of Philosophy in Biomedical } \\
\text { Sciences (PhD) } \\
\text { - Doctor of Dental Medicine (DMD) } \\
\text { - Master of Science (MSc) in Forensic } \\
\text { Odontology }\end{array}$ & $b$ \\
\hline
\end{tabular}




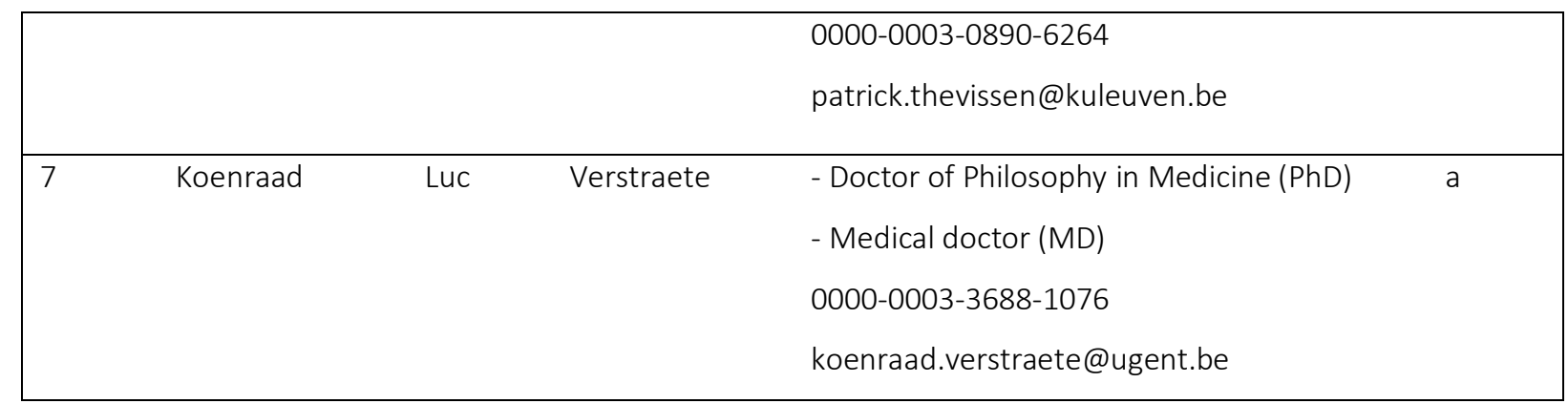

Affiliations:

a. Department of Diagnostic Sciences - Radiology, Ghent University, Corneel Heymanslaan 10, 9000 Ghent, Belgium

b. Department of Imaging and Pathology - Forensic Odontology, KU Leuven, Kapucijnenvoer 7 blok a bus 7001, 3000 Leuven, Belgium

c. Department of Oral and Maxillofacial Surgery, Leuven University Hospitals, Kapucijnenvoer 33, 3000 Leuven, Belgium

d. Diagnostic Department - Division of Radiology - Unit of Head and Neck and Maxillofacial Radiology, Geneva University Hospital, Rue Gabrielle-Perret-Gentil 4, 1211 Geneva 14, Switzerland

e. Department of Clinical Radiology, University Hospital Münster, Albert-Schweitzer-Campus 1, Münster 48149, Germany

f. Ludwig Boltzmann Institute for Clinical Forensic Imaging, Universitätsplatz 4, 8010 Graz, Austria

g. Medical University of Graz, Neue Stiftingtalstrasse 6, 8010 Graz, Austria

h. BioTechMed-Graz, Mozartgasse 12/II, 8010 Graz, Austria

i. Diagnostic \& Research Institute of Forensic Medicine, Medical University of Graz, Universitätsplatz 4, 8010 Graz, Austria

j. Forodont HB, Ängalagsvägen 419, 26995 Båstad, Sweden

Corresponding author and reprint info:

Jannick De Tobel

Department of Diagnostic Sciences - Radiology

Ghent University

Corneel Heymanslaan 10, 9000 Ghent, Belgium

Telephone +32(0)93324023

Fax $+32(0) 93324969$

jannick.detobel@ugent.be,

jannick.detobel@gmail.com

Declarations of interest: none. 


\section{Acknowledgements}

The authors wish to thank Andreas Schmeling for providing images of case examples, reaching out to fellow experts to provide case examples, and his critical appraisal of the manuscript. Furthermore, we gratefully acknowledge the contributions of Michiel de Haas, who also reviewed the manuscript, and Steffen Fieuws, who provided part of the graphs. We also want to thank $\varnothing$ yvind Bleka for providing the BioAlder results of the case examples. Finally, we thank Inès Phlypo for her critical appraisal of the manuscript.

\section{Funding}

Funding for this study was entirely provided by the Department of Diagnostic Sciences - Radiology at Ghent University.

\section{Overlap with other publications}

This review article was partly based on Chapter 12 in the PhD thesis of the first author, which was defended on March 22 ${ }^{\text {nd }}, 2019$ [De Tobel J (2019) Multi-factorial forensic age estimation: Combining magnetic resonance imaging of the third molars, the left wrist and both clavicles. PhD thesis, Ghent University - KU Leuven]. 


\section{ABBREVIATED TITLE PAGE}

Dental and skeletal imaging in forensic age estimation: disparities in current approaches and the continuing search for optimization

\section{Abstract}

Medical imaging for forensic age estimation in living adolescents and young adults continues to be a subject of discussions and controversies. Since age estimation based on medical imaging is wellstudied, it is the current gold standard. However, large disparities exist between the centers conducting age estimation, both between and within countries. The current review aimed to provide an overview of the most common approaches applied in Europe, with case examples illustrating the differences in imaging modalities, in staging of development, and in statistical processing of the age data. Additionally, the review aimed to take a look at the future, since several European research groups have intensified studies on age estimation, exploring four strategies for optimization: (1) increasing sample sizes of the reference populations, (2) combining single site information into multifactorial information, (3) avoiding ionizing radiation, and (4) fully automated analysis.

Keywords (MeSH): $\quad$ Age Determination by Skeleton

Age Determination by Teeth

Adolescent

Adult

Magnetic Resonance Imaging

\section{Abbreviations:}

MFA multi-factorial age estimation

SPIR signal presaturation with inversion recovery

SSA single site age estimation

T1 T1-weighted MR- sequence

T2 T2-weighted MR- sequence

VIBE volumetric interpolated breath-hold examination MR-sequence 


\section{MAIN BODY}

\section{Rationale behind forensic age estimation in the living}

Medical imaging for forensic age estimation in living adolescents and young adults continues to be a subject of discussions and controversies..$^{1-5}$ Forensic age estimation is mainly applied in asylum and criminal procedures to estimate the chronological age of the examinee, ${ }^{6,7}$ but is said to be imprecise and unethical. Indeed, precise age estimations are impossible due to inter-individual variation in development, $^{8-10}$ and lacking insights into the effects of the turbulent lives of the examinees.,11-13 Moreover, the exposure to ionizing radiation without a medical diagnostic or therapeutic indication is considered unethical by some professional organizations. ${ }^{2}$ Still, when applied appropriately, forensic age estimations are a necessary service to the examinee and to society. ${ }^{14-16}$ After all, a person's age is a key element of his/her identity, and is indispensable to function as an individual in society.

Since age estimation based on medical imaging is well-studied, it is the current gold standard. ${ }^{7}$ However, large disparities exist between the centers conducting age estimation, both between and within countries. ${ }^{17}$ Those disparities may be caused by the uncertainties (i.e. the measure of uncertainty around the point prediction of age) that always remain, regardless of the used method. Therefore, forensic age estimation in living adolescents and young adults continues to be the subject of research worldwide. The major attempt to reduce the uncertainty is by combining the information of different developing anatomical sites (multi-factorial age estimation, MFA). In particular, combining dental and skeletal information is recommended. ${ }^{7,18}$ Unfortunately, reports on how to combine this information appropriately remain scarce. ${ }^{19-24}$

Furthermore, some countries do not allow the use of medical imaging for forensic age estimation in the living. ${ }^{25}$ Although studies on alternative approaches that do not use medical images are starting to be published, they remain to be validated. ${ }^{26,27}$ Thus, to date, results with the smallest errors can only be obtained when medical images are used. Obviously, the age estimation obtained by the medical examinations should only be part of the entire age estimation procedure, which requires a multidisciplinary team that also assesses the examinee's history, documents, vulnerability and need for additional support. ${ }^{17}$

As an essential part of the age estimation procedure, the current review aimed to provide an overview of the most common approaches applied in Europe to estimate age in living adolescents and young adults based on medical imaging. Additionally, the review aimed to take a look at the future, considering approaches with the potential to become the new gold standard. 


\section{Disparities in current approaches}

\section{Recommendations and examples}

How results of age estimation should be reported depends on the questions of the commissioning authority. Experts advocate reporting a point prediction of age (i.e. the most likely age), together with the minimum age ${ }^{7}$ or an uncertainty interval (prediction interval). ${ }^{19-21,28,29}$ Additionally, some experts advocate to report a probability of being an adult (i.e. $\geq 18$ years in most countries). ${ }^{19,28,30}$ Recommendations of the international Study Group on Forensic Age Diagnostics (Arbeitsgemeinschaft für Forensische Altersdiagnostik, AGFAD) state that in case of adolescents and young adults, development of the third molars, the left hand/wrist, and the sternal ends of both clavicles (further on referred to as the AGFAD triad) should be assessed. ${ }^{7}$ To study the former two, radiographs are recommended, while computed tomography (CT) is recommended to study the clavicles. ${ }^{7}$ Note that the clavicles are only examined when the hand/wrist development is completed. Development of the third molars is mostly classified into Demirjian ${ }^{31}$ or Köhler ${ }^{32}$ stages, and including all four third molars performs best. ${ }^{33,34}$ When a third molar shows a closed apex, it has been proposed to additionally stage the radiographic visibility of the root pulp ${ }^{35}$ and/or the periodontal ligament. ${ }^{36}$ However, some authors have raised doubts about the reproducibility and applicability of those additional characteristics. ${ }^{37,38}$ Development of the hand/wrist is assessed with the Greulich-Pyle atlas, ${ }^{39}$ the Tanner-Whitehouse method, ${ }^{40}$ or the Thiemann-Nitz atlas. ${ }^{41}$ Development of the clavicles is classified into Schmeling stages $^{42}$ and Kellinghaus substages. ${ }^{43}$ Finally, age is derived from the staging results based on reference studies. Note that those results depend on the age distribution within the reference population. Furthermore, in adolescents and young adults, age estimation should always be performed sex-specific. To date, most reference studies are single site studies (single site age estimation, SSA) and there is no consensus on how multiple single site results should be combined into one single age estimation result.

To illustrate the most commonly applied approaches, detailed case examples are included in Figs. 1 to 4. Most countries even show a disparity in approaches between different centers. In those cases, we will refer to the city as well as the country. By contrast, in some countries, such as the Netherlands and Sweden, age estimation is centralized.

Fig. 1 shows how in Münster, Germany, the AGFAD recommendations are followed, and the minimum age principle is applied. ${ }^{44}$ According to that principle, the lower bound of the prediction interval is defined by the highest minimum age within any of the allocated developmental stages. The upper bound of the prediction interval is defined by the lowest maximum age within any of the allocated 
stages. However, no statements are made in the report about the highest possible age. In case of stage discrepancies between third molars or between clavicles, only the highest stage is considered.

Similarly, Fig. 2 shows how in Graz, Austria, the AGFAD recommendations are followed, but the minimal age principle is not applied. Instead, a minimum age is reported, based on the $99 \%$ confidence intervals from reference studies. Regarding the third molars, those intervals are calculated for all of them. Regarding the clavicles, the highest stage is considered in case of discrepancies between sides.

In Leuven, Belgium, the AGFAD recommendations are only partly followed, since radiographs are used to assess the clavicles (Fig. 3). ${ }^{45}$ However, recent studies consider clavicle radiographs obsolete for age estimation. ${ }^{46}$ The main focus in Leuven is on the teeth, since a model is available based on a large reference population $(\mathrm{N}=2513)^{47}$, and around 20 country-specific populations are available. The model takes the development of all four third molars into account, together with their possible agenetic status. Applying the model, a point prediction is reported, with a $95 \%$ prediction interval, and a probability to be an adult. Results of the hand/wrist and clavicles are then used to confirm the dental age estimation. In case of stage discrepancies between both clavicles, the lowest stage is considered. When discrepancies are obtained between the results of the three anatomical sites, the lowest age estimation results are considered decisive.

By contrast, the teeth are currently not examined in the Netherlands. ${ }^{48}$ Similar to Leuven, clavicle radiographs are made when the left hand/wrist radiograph shows completed development. However, the developing structures are not classified into stages. Instead, it is only determined if the physeal plate is open or closed. In case of stage discrepancies between both clavicles, the least developed side is considered. Consequently, only examinees with a mature left hand/wrist and two mature clavicles are considered adults.

A remarkable exception to forensic age estimation practice is Sweden (Fig. 4), where development of the mandibular third molars is assessed on a panoramic radiograph, and that of the left distal femur on magnetic resonance imaging (MRI, T1 fast spin echo sequence). ${ }^{49}$ Similar to the Netherlands, no stages are allocated. It is only determined if the third molars are fully developed (closed apex) and if the distal femur is fully mature (closed physeal plate). In case of stage discrepancies between the mandibular third molars, only the most developed one is considered. Males are considered to be adults if either a third molar or the distal femur is fully mature, whereas females are only considered adults if both structures are fully mature. ${ }^{49}$ The Swedish approach is controversial, since at the time it was adopted, no reference study had been published that lived up to the criteria set out by AGFAD. ${ }^{6}$ To date, larger reference studies have been published. ${ }^{50,51}$ 
Although the four presented case examples represent the most commonly applied approaches in Europe, other approaches are plentiful, with most of them being modifications of the presented approaches. An overview of the age estimation approaches applied throughout Europe can be found in the European Asylum Support Office's Practical Guide on Age Estimation. ${ }^{17}$ Finally, a general recommendation that is backed up by most experts in the field of age estimation is that each case should be assessed by two independent experts. In case of discrepancies, these experts should discuss the case to reach a consensus. At all times should the benefit of the doubt be granted.

\section{Implications and discussion}

Numerous reference and validation studies for age estimation based on dental radiographs, hand/wrist radiographs and clavicle CT have been published ${ }^{52-55}$, making SSA based on these imaging modalities a well-studied approach. Still, the dispersion between approaches may result in different age estimation outcomes. When a mere distinction is made between immature/mature, large numbers of false negatives and false positives can be assumed. In case of the Dutch approach, the number of false negatives (adults being considered as minors) will be high, which might be advantageous for the examinees, but increases the societal impact. By contrast, the Swedish approach might result in high numbers of false positives (minors being considered as adults), ${ }^{49}$ which is considered an ethically unacceptable error, and should be avoided in all age estimation procedures.

Consequently, several institutes allocate developmental stages to derive an age estimate, which allows for a more nuanced outcome. However, calculating a point prediction of age, an interval of uncertainty, and a probability to be adult requires a statistical procedure to combine the information. Some authors advocate a simple procedure, because that is insightful for all involved parties (e.g. examinee, requesting authority, medical professional, social worker). ${ }^{7,18,44}$ Moreover, all the necessary data can be derived from the published articles, so everyone can perform age estimation using these simple approaches. Conversely, other authors advocate a more complex statistical approach, whose results are considered to be closer to the truth, ${ }^{28,56}$ but are methodologically only transparent to a few 'super-specialists'. Still, if such an approach is validated in peer-reviewed scientific literature, its practical implementation should not be doubted. Unfortunately, the computational processing can only be performed by the authors themselves, unless an on-line tool would become available. 


\section{Continuing search for optimization}

The continuing migration waves in Europe, the lack of one age estimation approach that outperforms all others, and the continuing criticism regarding age estimation have prompted several research groups in Europe to intensify the studies on age estimation. Four strategies have been explored, with each of them related to the others:

1) increasing sample sizes of the reference populations,

2) combining SSA information into MFA information,

3) avoiding ionizing radiation,

4) fully automated analysis.

\section{Increasing sample sizes and combining information}

To address the first two strategies, Bleka et al. (2019) built a common model for age estimation based on data of several SSA studies using radiographs of the third molars and the hand/wrist (BioAlder). ${ }^{19}$ Their MFA method outperformed the SSA methods, with a mean width of the 95\% prediction intervals for males decreasing from 4.7 years (hand/wrist) and 5.7 years (third molars) to 4.5 years (combined). For females, the corresponding widths were 4.8, 5.9, and 4.6 years, respectively. In their calculations, they assumed development of the different anatomical sites to be conditionally independent (i.e. the developmental stages of the third molars do have any implications on the expected developmental state of the hand/wrist). This assumption has been supported by some authors, ${ }^{21,57}$ but has been rejected by others. ${ }^{19,20,28}$ Applying BioAlder to the case examples in Figs. 1 to 3 renders the results displayed in Table 1.

Retrospectively combining data of different SSA studies is only one approach to address the second strategy (i.e. combining SSA information into MFA information). Another possibility is to prospectively collect different SSA data simultaneously in the same individual. Note that combining this information into MFA information truly allows to study the conditional independence assumption. However, currently, it is only ethical to set up such prospective MFA studies in volunteers when no ionizing radiation is applied.

\section{Avoiding ionizing radiation}

\section{Computed tomography}

Before addressing the third strategy of optimization, it needs to be highlighted that modern CT techniques (e.g. cone beam $\mathrm{CT}$ ) require less irradiation than conventional $\mathrm{CT}$, which might increase 
their possibility of getting accepted for forensic diagnostics in the living. However, before these new techniques can be brought into forensic practice, they would require new reference studies. ${ }^{58}$ Such reference studies might become available soon, because they can be conducted retrospectively. That is, in case of SSA studies. By contrast, designing MFA studies retrospectively using ionizing radiation is not feasible, because of the low incidence of adolescents and young adults with radiographs or CTscans of several anatomical sites relevant for age estimation in a clinical setting. Consequently, no suitable MFA reference studies are available using radiographs and/or CT in living adolescents and young adults. Moreover, as highlighted earlier, setting up such a prospective MFA study using radiographs and/or CT in living volunteers is currently not considered ethical anymore.

\section{Ultrasound}

To address the third strategy of optimization, ultrasound has been studied for age estimation. ${ }^{59}$ Several SSA studies demonstrated that ultrasound examination of physeal development could be useful for age estimation, and research on this topic seems to continue. ${ }^{60}$ However, compared to the number of studies on radiographs, CT and MRI, reports on the use of ultrasound in forensic age estimation remain scarce. Although the lack of ionizing radiation and the low costs allow applying this imaging modality for MFA, no MFA studies have been reported. An explanation might be found in the many limitations of this imaging modality. Firstly, only the superficial side of the bone can be examined. An ossification center or remnants of the physeal plate might be hidden behind the outer contours of the bone. ${ }^{61}$ Moreover, dental development cannot be assessed by this imaging modality. Furthermore, the technique is highly operator-dependent and documenting the findings is harder than in other imaging modalities. Consequently, the evidence is hard to visualize for other involved parties and second opinions require a whole new examination (instead of a revision of the images, as can be done when radiographs, CT- or MRI-scans are available). ${ }^{59}$

\section{Magnetic resonance imaging}

Another way to address the second and third strategy of optimization is by using MRI. Over the past decade, MRI in forensic age estimation has evolved from a scarcely explored method to an extensively studied approach. ${ }^{62}$ To date, several research groups in Europe have collected MRI data for age estimation (Fig. 5). Among them, three centers have prospectively studied different anatomical sites and published their reports. They are the same centers who provided the conventional case examples in Figs. 1 to 3. Remarkably, the different centers independently came up with similar MR images to implement for age estimation, despite differences in scanners, coils and sequences. ${ }^{62}$

To illustrate the different MRI approaches, detailed case examples are included in Figs. 6 to 8. Fig. 6 shows how in Münster, Germany, four anatomical sites were examined, adding the left knee to the 
AGFAD triad (third molars, left hand/wrist, both clavicles). Although initial reports applied the same staging techniques as those for radiographs and $\mathrm{CT}$, more recently, the potential of MRI was put to use more extensively by a combined interpretation of two different sequence types (Figs 6e-j). ${ }^{51,63}$ Similar to the conventional approach in Münster, the minimum age principle is applied to estimate age on MRI. That way, the SSA data - derived from the published studies - can be combined for MFA in a simple manner.

In a collaboration between Ghent and Leuven, Belgium, a statistical model for age estimation based on MRI was developed, built on the one used for third molar development in radiographs. However, the MRI model creates a true combined result of the information from each of the anatomical sites (Fig. 7). Although the model is not freely available, the authors reported tables with sex-specific statistics for a list of possible combinations of stages that might be encountered in age estimation practice. They reported the tables for SSA studies, ${ }^{14,64,65}$ as well as for their MFA study. ${ }^{20}$ Furthermore, in SSA studies, the applicability of known staging techniques for radiographs and CT were evaluated for MRI. Regarding third molars, the authors proposed an MRI-specific staging technique, because the cemento-enamel junction cannot be defined unambiguously on MRI. ${ }^{64}$ Regarding the wrist, the known staging techniques could be applied without modifications. ${ }^{14}$ Finally, regarding the clavicles, the authors raised several concerns. ${ }^{65}$ They suggested including advanced substages of stage $3 a$, since they might allow further specifications around the age of 18. Furthermore, they suggested to discard the clavicles from analysis if they are in stages 1,4 , or 5 , since those stages might be confused. When an actual stage 1 would be mistaken for a wrongfully assigned stage 4 or 5 , the examinee would be considered as an adult, while in fact, he/she would very likely be a minor. This would be an ethically unacceptable error. However, their study population was too small to back up the suggestions statistically. ${ }^{65}$ Moreover, other groups have not reported the concern of confusing stages 1,4 , and 5 . Thus, this might be due to the MR-sequence or the calibration and experience of the observers.

The differences in MRI characteristics between the research groups impede simple merging of data (as was done in for instance Bleka et al. (2019) for radiographs). ${ }^{19}$ Indeed, the only comparative study between MRI approaches of different centers concluded that MR-sequence-specific reference studies should be applied, since the detection of small changing details such as the closing of the apex can be affected by MR-sequence parameters. ${ }^{66}$ Similarly, De Tobel et al. (2019) reported an inferior age estimation performance when the model based on wrist T1 TSE MRI was applied to T1 VIBE MRI data, and vice versa. ${ }^{14}$ Still, the next step in MRI for age estimation seems to be studying if the MRI data from different groups can safely be merged. ${ }^{30,62}$ If merging would be possible, that would generate strong reference data, comparable with the data that is currently available for radiographs. 
After all, the major limitation of the currently available MRI MFA studies is their relatively small study population. To date, only two suitable MFA studies have been published: Stern et al. (2019) ${ }^{24}$ and De Tobel et al. (2020). ${ }^{20}$ The first study included 322 males between 13 and 25 years of age, while the second study included 138 males and 160 females between 14 and 26 years of age. By contrast, MRI SSA studies included larger study populations up to 496 males $^{67}$ and 623 females. ${ }^{68}$ They were systematically reviewed in De Tobel et al. (2019). ${ }^{62}$ How large a number of females and males is required to develop an age estimation model is highly debatable. After all, a power analysis would rely on predefined levels of uncertainty. Obviously, the narrower the prediction intervals and the higher the diagnostic indices, the better. De Tobel et al. (2020) reported a mean width of the 95\% prediction intervals for males equal to 5.49 years, and for females 5.91 years. Those were obtained after correction for the rejected conditional independence assumption. However, it seems useless to set a predefined cut-off for the prediction intervals. With such a cut-off, presumably a sample size of thousands would be necessary, since an MFA approach should be sex-specific, and combines several anatomical structures (e.g. 8 structures in 3 sites in De Tobel et al. (2020)), which can be in a number of developmental stages (e.g. 6 to 8 stages taken into account in the model of De Tobel et al. (2020)). ${ }^{20}$ Therefore, it seems more logical to study which age indicators add information to the model and to report the age estimation performance that can be reached by them. Finally, one needs to realize that the added value of a certain anatomical site to the age estimation results depends on the demands of the requesting authority and the practical feasibility. It can be expected that adding more anatomical sites would improve the results, but if this improvement is only marginal, then the lower number of sites suffices.

Another limitation of the study populations in MRI studies is that most of them only included Caucasian participants, ${ }^{62}$ since MRI scanners are widespread in Europe and other wealthy countries. Whether age estimation performance of the illustrated methods is similar when they are applied to other ethnic groups, should be the focus of future research. Unfortunately, population-specific MRI data from other ethnical groups will be even harder to obtain than population-specific X-ray data.

The limited access to MR-scanners does not only hinder the design of reference studies. It might also hinder the practical implementation of the imaging modality for age estimation. Currently, waiting lists for MRI are relatively long. Therefore, the age estimation scans will need to be planned in between or after clinical scans. One possible solution would be to centralize the scanning procedure. In European countries like Denmark and Switzerland, a forensic institute is established, which features an MRscanner. In those cases, the scanner is immediately available, since its use only serves forensic purposes. A forensic MR-scanner might not even be necessary in every country. For age estimation, it could suffice to have forensic MR-scanners in the countries at Europe's outer borders. However, then 
a uniform European approach for forensic age estimation would be expedient, since the current lack of binding European guidelines would increase the decisional burden of the border countries.

Furthermore, compared to radiographs and CT, MRI takes significantly more time. To reduce the time, two possible solutions are being studied. Firstly, more powerful coils are currently available than the ones used in the MRI reference studies. Since the third molars and the clavicles might be scanned with one powerful head and neck coil, time would be saved, since changing the coil and the participant's position would no longer be needed. Secondly, acceleration of the MR-sequences has been proposed. Using compressed sensing with an open 0.3T MR-scanner, Terada et al. (2016) demonstrated that suitable hand/wrist images were still obtained with a 55 seconds acquisition time. ${ }^{69}$ Using a 3T MRscanner, Neumayer et al. (2020) presented a 4-minute approach to study the AGFAD triad of anatomical sites. ${ }^{70}$ These results look promising, but need to be validated before they can be generally applied.

Adding to the need of time, the process needs to be explained clearly, since the examinee needs to be slid in the bore, lie perfectly still, and the scanner is very loud. The explanation could be supported by a demonstration using a mock scanner. The combined explanation and demonstration takes about 20 minutes. Thus, in total, about one hour is needed to complete the MR-image acquisition for age estimation, when one of the illustrated MFA approaches is applied. Compared to radiographs and CT, the process is more demanding for all who are involved. Consequently, the costs for the requesting authority are higher, i.e. about twice as high, according to Belgian pricing. Still, although scientists can propose and validate alternative approaches to improve age estimation, politicians need to weigh the benefits in relation to the disadvantages and consider the practical implementation.

As a final concern, the explanation might not suffice to comfort an examinee if he/she suffers from claustrophobia. In some cases, starting the examination with the wrist scan can help, since the head is not in the bore during that scan. After that, the clavicle scan should be conducted and the third molars should be scanned last. Finally, the use of a high magnetic field is contra-indicated if the examinee has suffered war trauma, which might have left metal parts in the body, ${ }^{71}$ or in case of ferromagnetic implants.

\section{Fully automated analysis}

The illustrated MFA approaches have another disadvantage: they still require a human observer who stages development based on the images. Ideally, this observer is (1) an expert in age estimation, and (2) experienced in interpreting images of the applied modality. Too often age estimation is based on 
staging by an observer who lacks experience in at least one of both aspects. Furthermore, interobserver variability remains a downside to the procedure. It varies between anatomical structures, with knee and wrist bones reaching relatively high agreement, and clavicles being the most difficult to assess. ${ }^{62}$ The latter is due to motion artefacts caused by breathing and the large vessels, ${ }^{72}$ and due to the high prevalence of morphological variants. ${ }^{73}$

Therefore, automated image analysis and subsequent age estimation have been studied. Regarding dental development, a first step was taken by Banar et al. (2019) towards fully automated forensic age estimation based on a panoramic radiograph. ${ }^{74}$ Regarding hand/wrist radiographs, fully automated age estimation methods have successfully been developed and validated. ${ }^{75,76}$ However, when interpreting studies on automated bone age estimation, one needs to discern clinical methods from forensic methods. In clinical methods, the automated outcomes are compared with the bone age determined by expert radiologist. Conversely, to apply a method in a forensic context, the automated outcomes should be compared with the chronological age. Moreover, these bone age studies generally include populations up to age 19 , which is too close to the age threshold of 18 , relevant in forensic age estimation. Regarding clavicle CT, to our knowledge, automated approaches have not been reported.

Based on MRI, Stern et al. (2019) developed a fully automated method for MFA, using a deep convolutional neural network (DCNN) to assess the AGFAD triad of anatomical sites and derive age from them. ${ }^{24}$ Their approach is illustrated in Fig. 8. The method reached a promising age estimation performance, but since it is only available for males, it would be interesting to feed the DCNN MRIs from other research groups to expand the reference population. However, the DCNN will need to be adapted to handle the different MRIs. For instance, compared to the Austrian images, in Ghent/Leuven, third molars were not scanned with a 3D sequence, and the wrist scans did not include the hand.

Although automated approaches can be expected to render uniform (exactly reproducible) age estimation results, they cannot be expected to increase age estimation performance, which will always be limited by the inter-individual variation in development. After all, forensic age estimation uses dental and skeletal age to predict chronological age. This is the essential difference between forensic and clinical age estimation. 


\section{Conclusion}

Forensic age estimation in living adolescents and young adults continues to show disparities between countries and even between centers within the same country. Those disparities comprise imaging modalities, anatomical sites, reference population characteristics, staging techniques, and statistical approaches. Currently, no approach clearly outperforms another, although MFA is recommended over SSA. The continuing search for optimization has led to promising methods combining SSA information into MFA information, simultaneously increasing the size of the reference populations. As an ionizing radiation-free imaging modality, MRI shows the largest potential, and might become the first internationally accepted standardized method to estimate age. However, practical considerations need to be taken into account when this method is proposed to policy makers. In a next step to strive for the practical implementation of MRI in this field, the different research groups will need to join forces to validate age estimation approaches and eliminate observer-induced errors. Similar to other fields in radiology, MFA based on medical images is an excellent task for fully automated approaches. 


\section{References}

1 Axelsson I. Bone maturation cannot be used to estimate chronological age in asylum-seeking adolescents. Acta Paediatr 2019;108:590-592

2 Aynsley-Green A, Cole T, Crawley $\mathrm{H}$ et al. Medical, statistical, ethical and human rights considerations in the assessment of age in children and young people subject to immigration control. Br Med Bull 2012;102:17-42

Milani S, Benso L. Why we can't determine reliably the age of a subject on the basis of his maturation degree. J Forensic Leg Med 2019;61:97-101

4 Mishori R. The Use of Age Assessment in the Context of Child Migration: Imprecise, Inaccurate, Inconclusive and Endangers Children's Rights. Children (Basel) 2019;6

5 Ording Muller LS, Offiah A, Adamsbaum C et al. Bone age for chronological age determination statement of the European Society of Paediatric Radiology musculoskeletal task force group. Pediatr Radiol 2019;49:979-982

Schmeling A, Grundmann C, Fuhrmann A et al. Criteria for age estimation in living individuals. Int J Legal Med 2008;122:457-460

7 Schmeling A, Dettmeyer R, Rudolf E, Vieth V, Geserick G. Forensic Age Estimation. Dtsch Arztebl Int 2016;113:44-50

8 Thevissen PW, Alqerban A, Asaumi J et al. Human dental age estimation using third molar developmental stages: Accuracy of age predictions not using country specific information. Forensic Sci Int 2010;201:106-111

9 Thevissen PW, Fieuws S, Willems G. Human third molars development: Comparison of 9 country specific populations. Forensic Sci Int 2010;201:102-105

10 Schmeling A, Reisinger W, Loreck D et al. Effects of ethnicity on skeletal maturation: consequences for forensic age estimations. Int J Legal Med 2000;113:253-258

11 Elamin F, Liversidge HM. Malnutrition has no effect on the timing of human tooth formation. PLoS One 2013;8:e72274

Meijerman L, Maat GJR, Schulz R, Schmeling A. Variables affecting the probability of complete fusion of the medial clavicular epiphysis. Int J Legal Med 2007;121:463-468

13 Schmeling A, Schulz R, Danner B, Rosing FW. The impact of economic progress and modernization in medicine on the ossification of hand and wrist. Int J Legal Med 2006;120:121-126

De Tobel J, Hillewig E, de Haas MB et al. Forensic age estimation based on T1 SE and VIBE wrist MRI: do a one-fits-all staging technique and age estimation model apply? Eur Radiol 2019;26:2924-2935

Schmeling A. [The current medical-ethical debate on forensic age estimation in unaccompanied minor refugees] [Master's thesis]. Westfälische Wilhelms-Universität Münster; 2018: Forensic Odontostomatol 2012;30 Suppl 1:84-102

Practical Guides Series. Malta; 2018

18 Schumacher G, Schmeling A, Rudolf E. Medical age assessment of juvenile migrants: An analysis of age marker-based assessment criteria. In. Luxembourg: Joint Research Centre (JRC) Science for Policy Report, European Union; 2018

Bleka O, Rolseth V, Dahlberg PS et al. BioAlder: a tool for assessing chronological age based on two radiological methods. Int J Legal Med 2019;133:1177-1189

De Tobel J, Fieuws S, Hillewig E et al. Multi-factorial age estimation: a Bayesian approach combining dental and skeletal magnetic resonance imaging Forensic Sci Int 2020;306:[E-pub ahead of print]

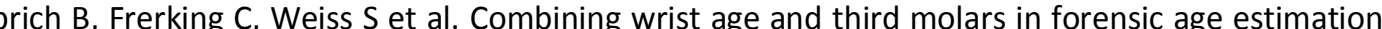
how to calculate the joint age estimate and its error rate in age diagnostics. Ann Hum Biol 2015;42:389-396

Kumagai A, Willems G, Franco A, Thevissen P. Age estimation combining radiographic information of two dental and four skeletal predictors in children and subadults. Int J Legal Med 2018;132:1769-1777

Schmidt S, Schramm D, Ribbecke $S$ et al. [Forensic age estimation in juveniles and young adults: Reducing the range of scatter in age diagnosis by combining different methods]. Arch Kriminol 2016;237:25-37

24 Stern D, Payer C, Giuliani N, Urschler M. Automatic Age Estimation and Majority Age Classification From Multi-Factorial MRI Data. IEEE J Biomed Health Inform 2019;23:1392-1403 

Altersdiagnostik der Deutschen Gesellschaft für Rechtsmedizin. Rechtsmedizin 2004;14:123-126 Sypek SA, Benson J, Spanner KA, Williams JL. A holistic approach to age estimation in refugee children. J Paediatr Child Health 2016;52:614-620 Vaska Al, Benson J, Eliott JA, Williams J. Age determination in refugee children: A narrative history tool for use in holistic age assessment. J Paediatr Child Health 2016;52:523-528 Fieuws S, Willems G, Larsen-Tangmose $S$ et al. Obtaining appropriate interval estimates for age when multiple indicators are used: evaluation of an ad-hoc procedure. Int J Legal Med 2016;130:489-499 Thevissen PW, Fieuws S, Willems G. Human dental age estimation using third molar developmental stages: does a Bayesian approach outperform regression models to discriminate between juveniles and adults? Int J Legal Med 2010;124:35-42

De Tobel J. Multi-factorial forensic age estimation: Combining magnetic resonance imaging of the third molars, the left wrist and both clavicles [PhD thesis]. Ghent Ghent University - KU Leuven; 2019: 314 Demirjian A, Goldstein H, Tanner JM. A new system of dental age assessment. Hum Biol 1973;45:211227

Köhler S, Schmelzle R, Loitz C, Puschel K. [Development of wisdom teeth as a criterion of age determination]. Ann Anat 1994;176:339-345

Rozkovcova E, Dostalova T, Markova M, Broukal Z. The third molar as an age marker in adolescents: new approach to age evaluation. J Forensic Sci 2012;57:1323-1328

Sironi E, Pinchi V, Pradella F et al. Bayesian networks of age estimation and classification based on dental evidence: A study on the third molar mineralization. J Forensic Leg Med 2018;55:23-32

Olze A, Solheim T, Schulz R, Kupfer M, Schmeling A. Evaluation of the radiographic visibility of the root pulp in the lower third molars for the purpose of forensic age estimation in living individuals. Int $J$ Legal Med 2010;124:183-186

Olze A, Solheim T, Schulz R et al. Assessment of the radiographic visibility of the periodontal ligament in the lower third molars for the purpose of forensic age estimation in living individuals. Int J Legal Med 2010;124:445-448

Al Qattan F, Alzoubi EE, Lucas V et al. Root Pulp Visibility as a mandibular maturity marker at the 18year threshold in the Maltese population. Int J Legal Med 2019 DOI: 10.1007/s00414-019-02155-5 Chaudhary MA, Liversidge HM. A radiographic study estimating age of mandibular third molars by periodontal ligament visibility. J Forensic Odontostomatol 2017;35:79-89

39 Greulich W, Pyle SI. Radiographic atlas of skeletal development of the hand and wrist. 2nd ed. Stanford, CA: Stanford University Press; 1959

Tanner JM, Whitehouse RH, Cameron $\mathrm{N}$ et al. Assessment of skeletal maturity and prediction of adult height (TW2 method). 2nd ed. London: Academic Press Limited; 1983

Thiemann HH, Nitz I, Schmeling A. [Röntgenatlas of the normal hand in childhood]. Stuttgart, New York: Georg Thieme Verlag; 2006

42 Schmeling A, Schulz R, Reisinger W et al. Studies on the time frame for ossification of the medial clavicular epiphyseal cartilage in conventional radiography. Int J Legal Med 2004;118:5-8

Kellinghaus $M$, Schulz R, Vieth $V$ et al. Enhanced possibilities to make statements on the ossification status of the medial clavicular epiphysis using an amplified staging scheme in evaluating thin-slice CT scans. Int J Legal Med 2010;124:321-325

Rudolf E, Kramer J, Gebauer A et al. Standardized medical age assessment of refugees with questionable minority claim-a summary of 591 case studies. Int J Legal Med 2015;129:595-602

Thevissen P, Willems G. [The Triple Test: The K.U.Leuven-protocol for age estimation of unaccompanied minor refugees]. In: Aps JKM, Brand HS, Duyck J et al eds, Het Tandheelkundig Jaar 2013. Houten: Bohn Stafleu van Loghum; 2013: 175-190 Wittschieber D, Ottow C, Schulz R et al. Forensic age diagnostics using projection radiography of the clavicle: a prospective multi-center validation study. Int J Legal Med 2016;130:213-219

Gunst K, Mesotten K, Carbonez A, Willems G. Third molar root development in relation to chronological age: a large sample sized retrospective study. Forensic Sci Int 2003;136:52-57 Netherlands Forensic Institute. [Protocol Age Assessment]. In; 2014 2019;133:613-623 the definite relevance in bony fusion of the distal femoral- and the proximal tibial epiphyses using closest-to-bone T1 TSE sequence. Eur Radiol 2017;27:5041-5048 
Vieth V, Schulz R, Heindel W et al. Forensic age assessment by 3.0T MRI of the knee: proposal of a new MRI classification of ossification stages. Eur Radiol 2018;28:3255-3262

52 Thevissen PW. Dental age estimation: striving for an optimal approach [PhD thesis]. Leuven Leuven University Press; 2013: Haglund M, Mornstad H. A systematic review and meta-analysis of the fully formed wisdom tooth as a radiological marker of adulthood. Int J Legal Med 2018;133:231-239 Alshamrani K, Messina F, Offiah AC. Is the Greulich and Pyle atlas applicable to all ethnicities? A systematic review and meta-analysis. Eur Radiol 2019 DOI: 10.1007/s00330-018-5792-5 Hermetet C, Saint-Martin P, Gambier A et al. Forensic age estimation using computed tomography of the medial clavicular epiphysis: a systematic review. Int J Legal Med 2018;132:1415-1425 Hum Biol 2015;42:368-378 Varkkola O, Ranta H, Metsaniitty M, Sajantila A. Age assessment by the Greulich and Pyle method compared to other skeletal X-ray and dental methods in data from Finnish child victims of the Southeast Asian Tsunami. Forensic Sci Med Pathol 2011;7:311-316 Maret D, Peters OA, Dedouit F, Telmon N, Sixou M. Cone-Beam Computed Tomography: a useful tool for dental age estimation? Med Hypotheses 2011;76:700-702

59 Schulz R, Schmidt S, Pfeiffer H, Schmeling A. [Sonographic examinations of various skeletal regions]. Rechtsmedizin 2014;24:480-484 ossification of the medial clavicle epiphysis using ultrasound methods. Forensic Sci Int 2018;284:161166

Gonsior M, Ramsthaler F, Birngruber C, Obert M, Verhoff MA. The completely fused medial clavicular epiphysis in high-frequency ultrasound scans as a diagnostic criterion for forensic age estimations in the living. Int J Legal Med 2016;130:1603-1613 De Tobel J, Bauwens J, Parmentier GIL et al. The use of magnetic resonance imaging in forensic age estimation of living children and subadults systematically reviewed. Pediatr Radiol 2019;[Revision submitted after peer review]

Ottow C, Schmidt S, Heindel W. Forensic Age Assessment by 3.0T MRI of the Wrist. Adaption of the Vieth-Classification. Submitted 2019

64 De Tobel J, Phlypo I, Fieuws S et al. Forensic age estimation based on development of third molars: a staging technique for magnetic resonance imaging. J Forensic Odontostomatol 2017;35:117-140 imaging: pitfalls and recommendations for age estimation. J Magn Reson Imaging 2019 DOI: 10.1002/jmri.26889 [Epub ahead of print]

De Tobel J, Parmentier GIL, Phlypo I et al. Magnetic resonance imaging of third molars in forensic age estimation: comparison of the Ghent and Graz protocols focusing on apical closure. Int J Legal Med 2019;133:583-592

Dvorak J, George J, Junge A, Hodler J. Age determination by magnetic resonance imaging of the wrist in adolescent male football players. Br J Sports Med 2007;41:45-52

Ekizoglu O, Hocaoglu E, Can $1 O$ et al. Spheno-occipital synchondrosis fusion degree as a method to estimate age: A preliminary, magnetic resonance imaging study. Aust J Forensic Sci 2016;48:159-170

Terada Y, Tamada D, Kose $\mathrm{K}$ et al. Acceleration of skeletal age MR examination using compressed sensing. J Magn Reson Imaging 2016;44:204-211

Neumayer B, Lesch A, Thaler F et al. The four-minute approach revisited: accelerating MRI-based multi-factorial age estimation. Int J Legal Med 2020;Accepted

Tangmose S, Jensen KE, Villa C, Lynnerup N. Forensic age estimation from the clavicle using 1.0T MRIPreliminary results. Forensic Sci Int 2014;234:7-12

De Tobel J, van Wijk M, Alberink I et al. The influence of motion artifacts on magnetic resonance imaging of the clavicles for age estimation. Int J Legal Med 2019;Accepted on November 17, 2019 collected from sternoclavicular thin-slice CT-studies of 2820 male borderline-adults. Int J Legal Med 2019;133:1517-1528

74 Banar N, Bertels J, Laurent F et al. Fully automated third molar development staging in panoramic radiographs. 2019;Submitted on November 25, 2019

75 Thodberg HH, van Rijn RR, Jenni OG, Martin DD. Automated determination of bone age from hand Xrays at the end of puberty and its applicability for age estimation. Int J Legal Med 2017;131 
Halabi SS, Prevedello LM, Kalpathy-Cramer J et al. The RSNA Pediatric Bone Age Machine Learning Challenge. Radiology 2019;290:498-503

77 Olze A, van NP, Schmidt S et al. Studies on the progress of third-molar mineralisation in a Black African population. Homo 2006;57:209-217

78 Tise M, Mazzarini L, Fabrizzi G et al. Applicability of Greulich and Pyle method for age assessment in forensic practice on an Italian sample. Int J Legal Med 2011;125:411-416

79 Wittschieber D, Schulz R, Vieth $V$ et al. The value of sub-stages and thin slices for the assessment of the medial clavicular epiphysis: a prospective multi-center CT study. Forensic Sci Med Pathol 2014;10:163-169

80 Schmeling A, Kreitner K-F, Heindel W, Vieth V. [Imaging in forensic age estimation of youngsters and young adults]. Radiologie up2date 2019;19:63-75

81 Chaumoitre K, Saliba-Serre B, Adalian P et al. Forensic use of the Greulich and Pyle atlas: prediction intervals and relevance. Eur Radiol 2017;27:1032-1043

82 Guo Y, Olze A, Ottow C et al. Dental age estimation in living individuals using 3.0 T MRI of lower third molars. Int J Legal Med 2015;129:1265-1270

83 Schmidt S, Ottow C, Pfeiffer $\mathrm{H}$ et al. Magnetic resonance imaging-based evaluation of ossification of the medial clavicular epiphysis in forensic age assessment. Int J Legal Med 2017;131:1665-1673 

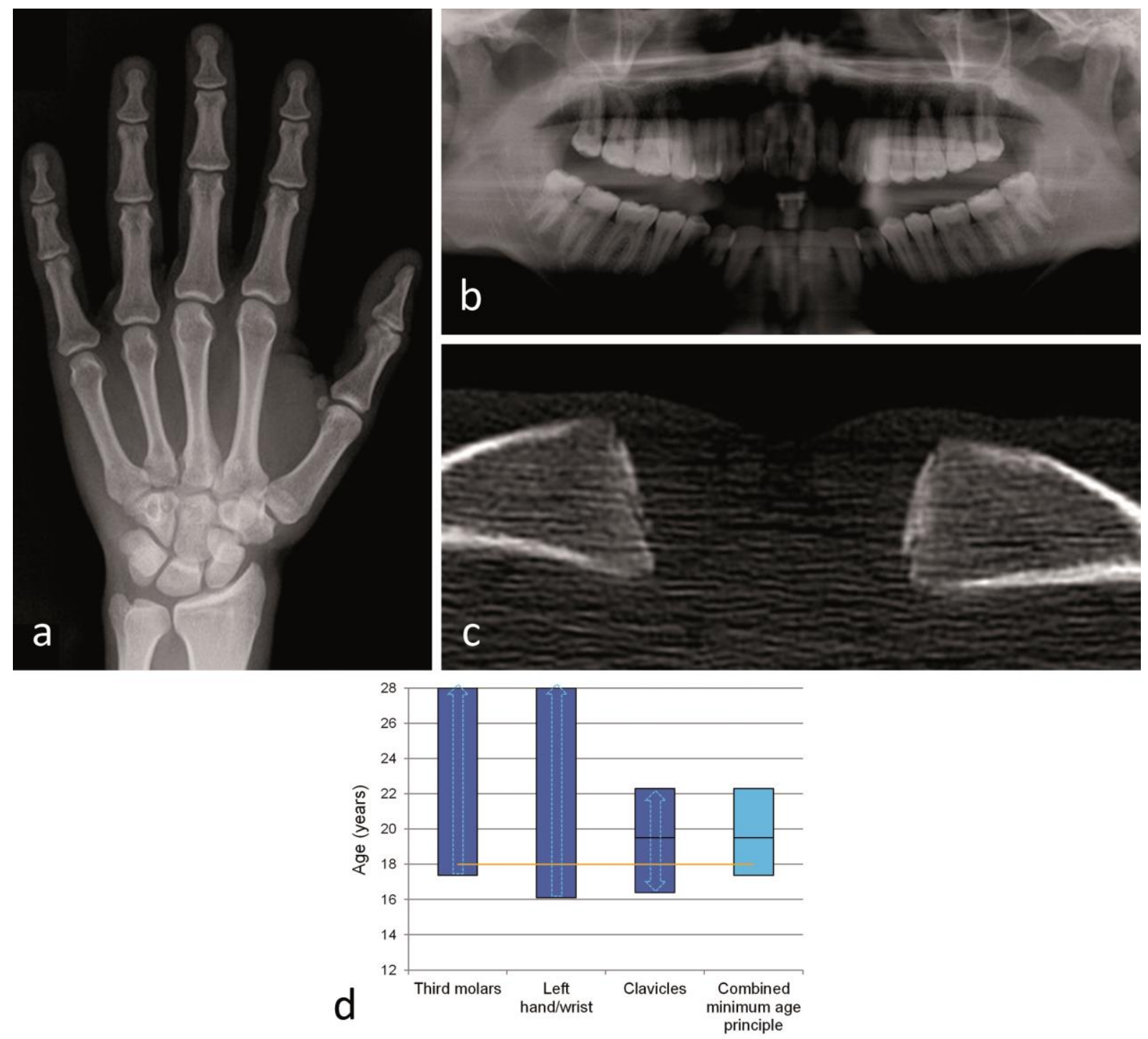

Fig. 1 Male case example from Münster, Germany. (a) The hand/wrist radiograph shows completed development. Thus, a CT of both clavicles is made (c), which shows a Kellinghaus stage 3a in both clavicles. Note that the axial slice is used for the assessment. (b) All four third molars display a closed apex. (d) When the final stage of development is reached, the boxplots only show minimum age. The individual can be of any age higher than that minimum age. When the final stage is not reached, the boxplots show minimum age, median, and maximum age based on reference studies. ${ }^{77-79}$ Applying the minimum age principle, the lower bound of the estimated age interval is defined by the highest minimum age, which is 17.38 years (third molars). Thus, it cannot be excluded that this person is a minor. The upper bound of the estimated age interval is defined by the lowest maximum age, which is 22.30 years (clavicles). However, no statements are made in the report about the highest possible age. 
The reported most probable age is 19 years, which corresponds with the rounded down mean age based on the clavicles, since the other structures have completed development.

( $a, b, c$ Reproduced with permission from the publisher from Schmeling A, Kreitner K-F, Heindel W, Vieth V. [Imaging in forensic age estimation of youngsters and young adults]. Radiologie up2date 2019;19:63-75. ${ }^{80}$ ) 

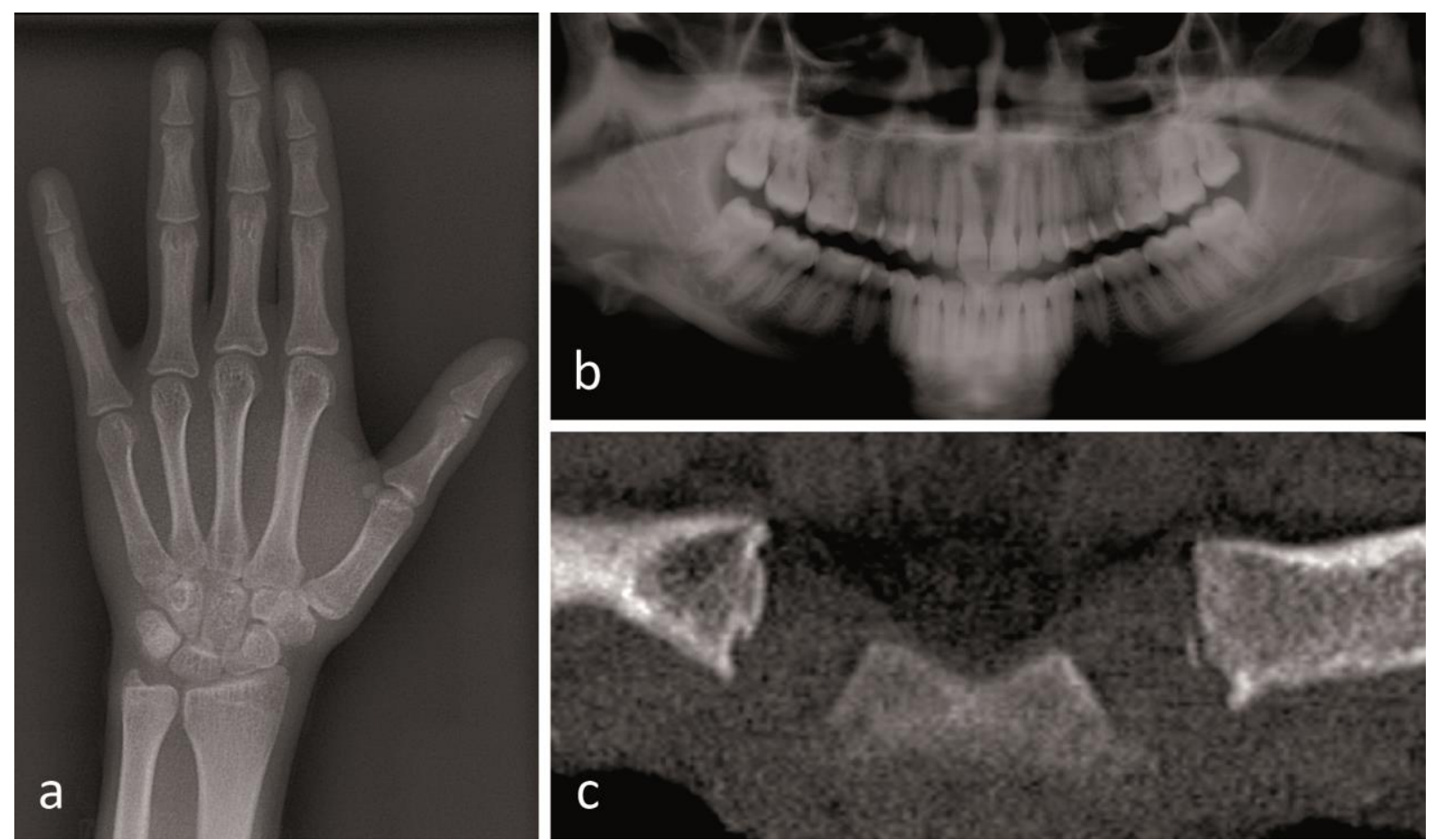

Fig. 2 Female case example from Graz, Austria. (a) The hand/wrist radiograph shows completed development. Thus, a CT of both clavicles is made (c), which shows a Kellinghaus stage 3a in the right clavicle, and Kellinghaus stage $2 a$ in the left clavicle. The higher stage is considered for the age estimation. Note that the coronal slice is depicted. For the assessment, both the axial and the coronal planes are considered. (b) All four third molars display a closed apex.

A minimum age of 17.7 years old is reported, based on $99 \%$ confidence intervals calculated from reference studies. ${ }^{43,77}$ Additionally, the report states that minority cannot be ruled out. 


Fig. 3 Male case example from Leuven, Belgium. (a) Upper third molars are in Köhler stage 8, while the lower left is in stage 6, and the lower right is in stage 7. (b) The hand/wrist radiograph shows completed development. (c) The postero-anterior radiograph suggests Schmeling stage 3 in both clavicles, which is confirmed on $10-15^{\circ}$ oblique radiographs $(d, e)$.

(f) Posterior density curve for the observed combination of third molars' Köhler stages $8867 .{ }^{29}$ The point prediction of age equals 17.6 years old, with 95\% prediction interval [14.4 - 21.3], and a probability to be an adult equal to $41 \%$.

(g) The boxplots show the 95\% prediction intervals and the point prediction of age, based on reference studies. ${ }^{29,42,81}$ Note that for the hand/wrist the final stage of development is reached. Therefore, the age distribution in the corresponding boxplot is highly affected by the study population. Consequently, the combined result takes into account the arrow instead of the boxplot. This case shows a discrepancy between age estimation based on dental and skeletal development. Unfortunately, to date, there is no appropriate statistical method reported in literature which combines the information of these three anatomical sites based on radiographs. Therefore, the benefit of the doubt is granted in this case, and the dental results are considered decisive. Note that the skeletal results do not exclude the dental results. 


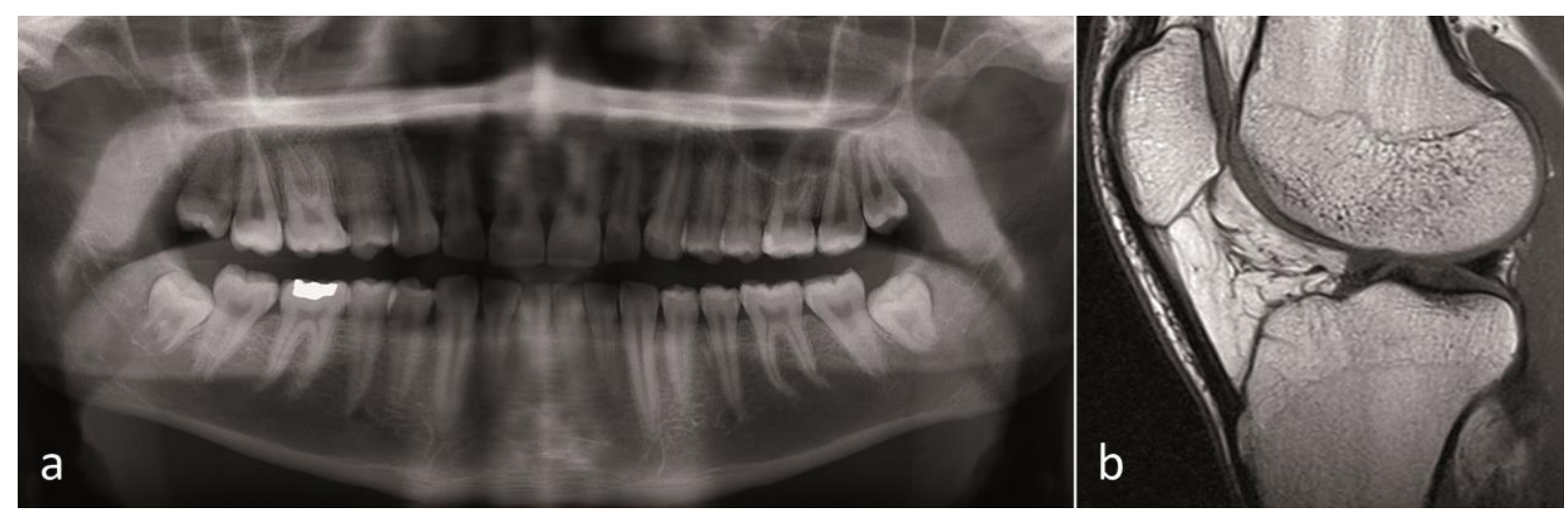

Fig. 4 Male case example from Sweden. (a) Panoramic radiograph shows the lower third molars have not reached the final stage of development. (b) T1 fast spin echo MRI of the knee. Initially, the physeal plate of the distal femur was assessed to be closed. Since this is a male case, this finding suggested him to be 18 years or older. However, in a second opinion, both the distal femur and the proximal tibia were assessed to be in Kellinghaus stage 3c, which implied that he should be considered as a minor. 


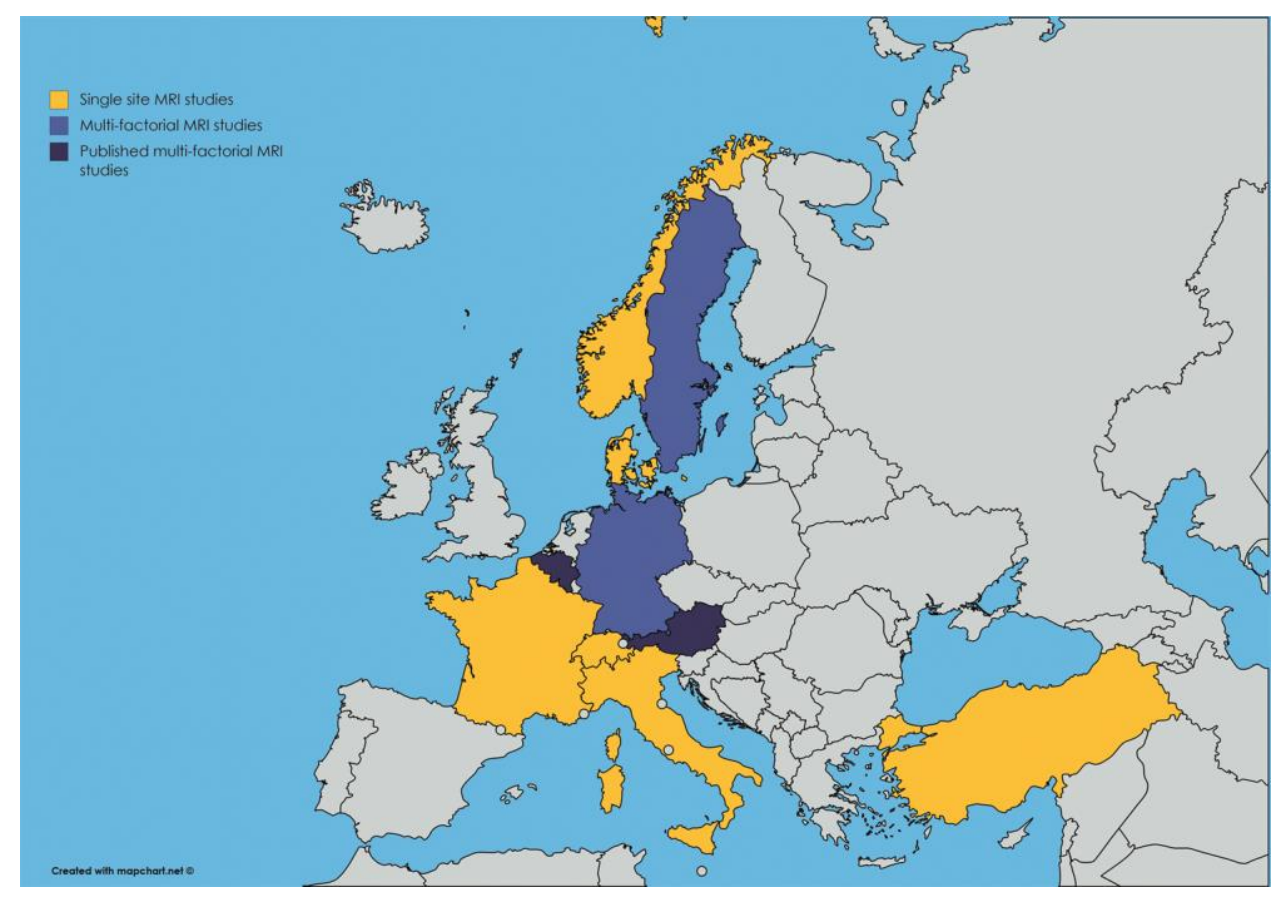

Fig. 5 European countries in which research on the use of MRI in age estimation has been conducted or is still ongoing. 

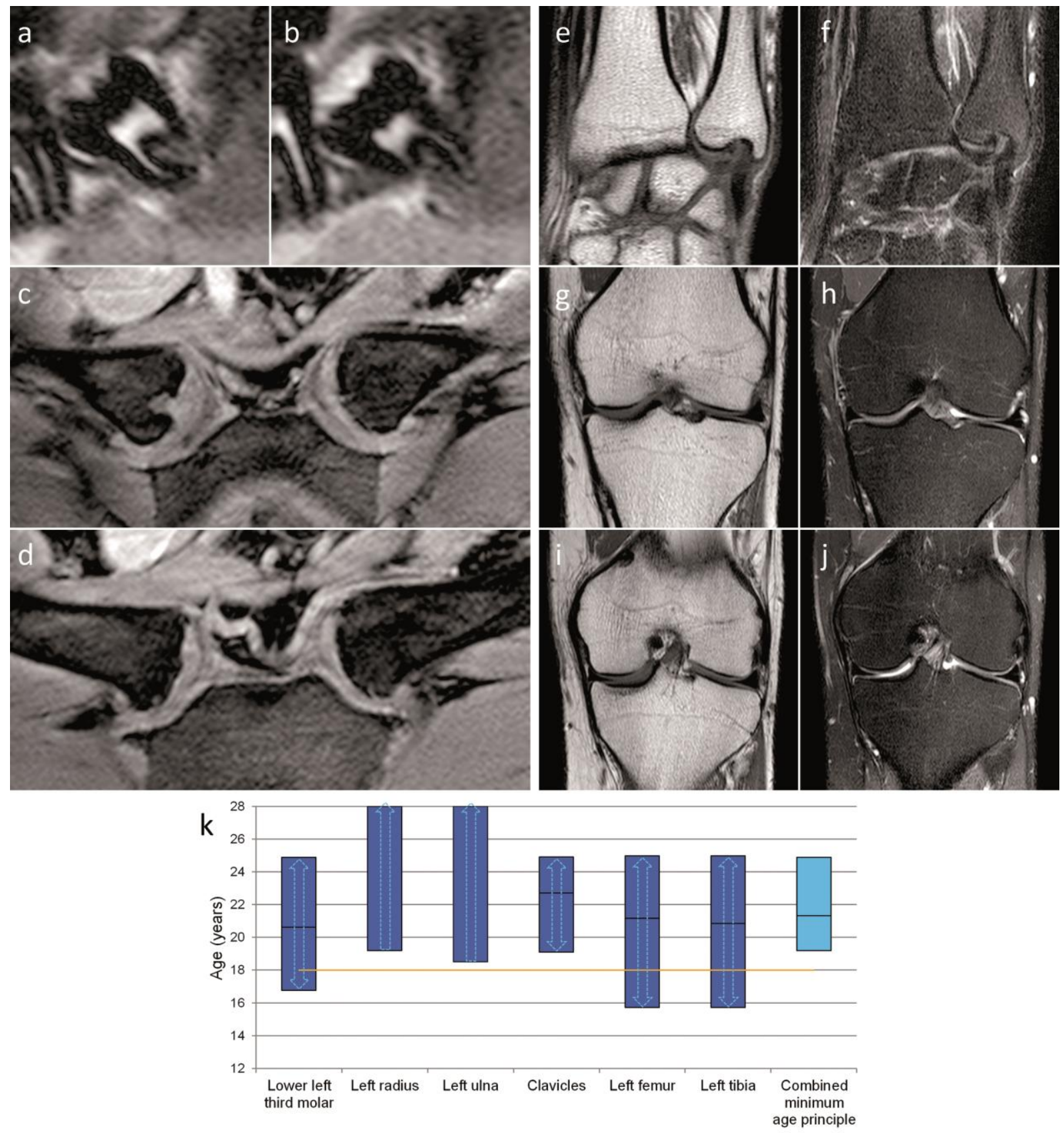

Fig. 6 Male MRI case example from Münster, Germany.

(a, b) T2 turbo spin echo of the lower left third molar shows it is in Demirjian stage G. (a) Mesial root apex. (b) Distal root apex. (c, d) T1 3D fast field echo of the clavicles. (c) The right clavicle is excluded because it is a morphological variant. (d) The left clavicle is in Kellinghaus stage 3c. (e,f) T1 turbo spin echo and T2 turbo spin echo SPIR of the left wrist show both the radius and ulna are in Vieth stage 6. (g-j) T1 turbo spin echo and T2 turbo spin echo SPIR of the left knee. $(\mathbf{g}, \mathbf{h})$ The distal femur is in Vieth stage 5. ( $(, j)$ The proximal tibia is also in Vieth stage 5 . ( $(\mathbf{k})$ When the final stage of development is reached, the boxplots only show minimum age. The individual can be of any age higher than that 
minimum age. When the final stage is not reached, the boxplots show minimum age, median, and maximum age based on reference studies. ${ }^{51,63,82,83}$ Applying the minimum age principle, the lower bound of the estimated age interval is defined by the highest minimum age, which is 19.19 years (radius). Thus, it can be excluded that this person is a minor. The upper bound of the estimated age interval is defined by the lowest maximum age, which is 24.89 years (lower left third molar). The most probable age is 21 years, which corresponds with the overall evaluation of the means, based only on the developing structures (thus excluding the radius and ulna). 


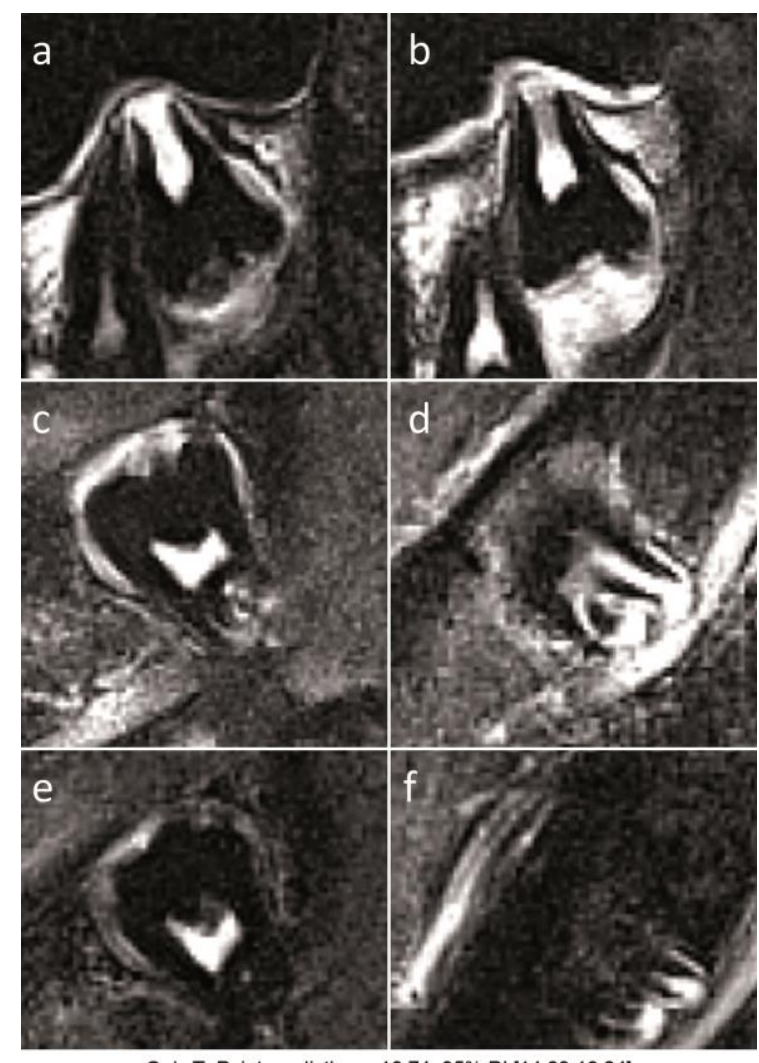

Only $\mathrm{T}$ Point prediction $=16.74 ; 95 \% \mathrm{PI}[14.39 ; 19.24]$ $P(\geq 18 y)=0.134$

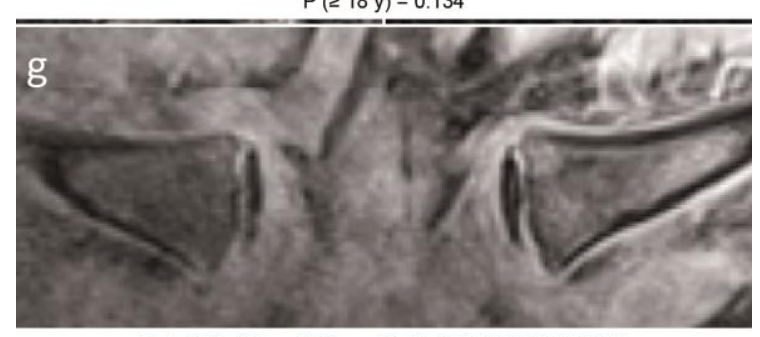

Only C Point prediction $=18.41 ; 95 \% \mathrm{PI}[14.00 ; 23.71]$

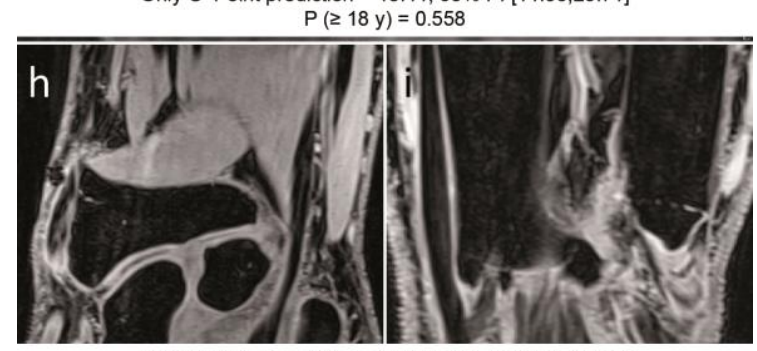

Only W Point prediction $=18.10 ; 95 \%$ PI $[16.26 ; 20.18]$ $P(\geq 18 y)=0.47$

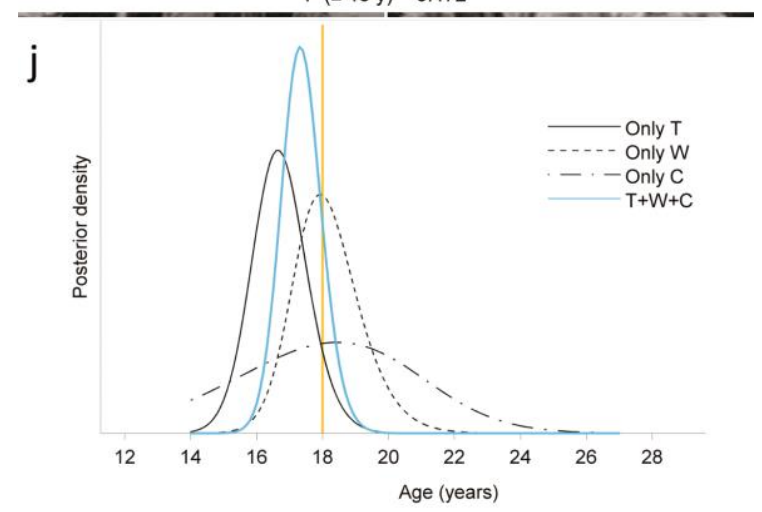

$\mathrm{T}+\mathrm{W}+\mathrm{C}$ Point prediction $=17.38 ; 95 \%$ PI $[15.77 ; 19.09]$ $P(\geq 18 y)=0.207$
Fig. 7 Male MRI case example from Ghent/Leuven, Belgium.

(a-f) T2 turbo spin echo of the third molars shows they are all in De Tobel stage 4. (a, b) Palatal roots of third molars 18 and 28, respectively. (c, d) Crown and apices of third molar 38, respectively. (e, f) Crown and apices of third molar 48 , respectively. (g) T1 gradient echo VIBE of the clavicles shows they are both in Wittschieber stage 3ab. (h, i) T1 VIBE of the left wrist. (h) The distal radius is in Kellinghaus stage 3c. (i) The distal ulna is in Kellinghaus stage 3c. In this slice, it appears to be in a lower stage, but scrolling through the sequence demonstrates that most of the physeal plate is bridged. (j) Posterior density curves for single site age estimation and for multi-factorial age estimation. ${ }^{20}$ This person will be considered a minor. 




Fig. 8 Male MRI case example from Graz, Austria.

(a-d) Proton density weighted 3D turbo spin echo of the third molars. $(a, b)$ Palatal roots of third molars 18 and 28, respectively. (c, d) Apices of third molars 38 and 48, respectively. (e) T1 3D gradient echo of both clavicles. (f-h) T1 3D gradient echo of the left hand/wrist.

The automated approach ${ }^{24}$ takes into account cubic and beam-shaped regions of interest including the entire four third molars, the sternal ends of both clavicles, and thirteen physeal regions of the hand/wrist (proximal physis of the proximal phalanges, distal physis of the metacarpals (f), proximal physis of the first metacarpal (h), distal physis of the ulna, distal physis of the radius $(\mathbf{f}, \mathbf{g})$ ). Based on the reference population, a point prediction of 17.17 years of age is obtained, and the individual is classified as a minor. Currently, the approach is not able to generate prediction intervals or probabilities to be an adult. This is part of ongoing further developments by the Austrian researchers. 
Tables



\begin{tabular}{|c|c|c|c|c|}
\hline & Anatomical site & Prediction intervals & & $\begin{array}{l}\text { Percentage of } \\
\text { individuals }<18 \text { years }\end{array}$ \\
\hline \multirow[t]{3}{*}{$\begin{array}{l}\text { Male case } \\
\text { example Fig. } 1\end{array}$} & $\begin{array}{l}\text { Third molar } 38 \text { Demirjian } \\
\text { stage } \mathrm{H}\end{array}$ & $\begin{array}{l}87.5 \% \text { of individuals will be more than } 18 \\
\text { years } 3 \text { months }\end{array}$ & $\begin{array}{l}97.5 \% \text { of individuals will be more than } 17 \\
\text { years } 2 \text { months }\end{array}$ & $9.1 \%$ \\
\hline & $\begin{array}{l}\text { Hand/wrist Greulich-Pyle } \\
\text { standard } 19 \text { years }\end{array}$ & $\begin{array}{l}87.5 \% \text { of individuals will be more than } 17 \\
\text { years } 6 \text { months }\end{array}$ & $\begin{array}{l}97.5 \% \text { of individuals will be more than } 16 \\
\text { years } 3 \text { months }\end{array}$ & $23 \%$ \\
\hline & Combined & $\begin{array}{l}87.5 \% \text { of individuals will be more than } 18 \\
\text { years } 8 \text { months }\end{array}$ & $\begin{array}{l}97.5 \% \text { of individuals will be more than } 17 \\
\text { years } 10 \text { months }\end{array}$ & $<5 \%$ \\
\hline \multirow[t]{3}{*}{$\begin{array}{l}\text { Female case } \\
\text { example Fig. } 2\end{array}$} & $\begin{array}{l}\text { Third molar } 38 \text { Demirjian } \\
\text { stage } \mathrm{H}\end{array}$ & $\begin{array}{l}87.5 \% \text { of individuals will be more than } 18 \\
\text { years } 7 \text { months }\end{array}$ & $\begin{array}{l}97.5 \% \text { of individuals will be more than } 17 \\
\text { years } 5 \text { months }\end{array}$ & $6.1 \%$ \\
\hline & $\begin{array}{l}\text { Hand/wrist Greulich-Pyle } \\
\text { standard } 18 \text { years }\end{array}$ & $\begin{array}{l}87.5 \% \text { of individuals will be more than } 16 \\
\text { years } 6 \text { months }\end{array}$ & $\begin{array}{l}97.5 \% \text { of individuals will be more than } 15 \\
\text { years } 4 \text { months }\end{array}$ & $55 \%$ \\
\hline & Combined & $\begin{array}{l}87.5 \% \text { of individuals will be more than } 18 \\
\text { years } 9 \text { months }\end{array}$ & $\begin{array}{l}97.5 \% \text { of individuals will be more than } 17 \\
\text { years } 9 \text { months }\end{array}$ & $<5 \%$ \\
\hline \multirow[t]{3}{*}{$\begin{array}{l}\text { Male case } \\
\text { example Fig. } 3\end{array}$} & $\begin{array}{l}\text { Third molar } 38 \text { Demirjian } \\
\text { stage } E\end{array}$ & $\begin{array}{l}75 \% \text { of individuals will be between } 13 \text { years } \\
8 \text { months and } 17 \text { years } 10 \text { months }\end{array}$ & $\begin{array}{l}95 \% \text { of individuals will be between } 12 \text { years } \\
5 \text { months and } 19 \text { years } 4 \text { months }\end{array}$ & $89 \%$ \\
\hline & $\begin{array}{l}\text { Hand/wrist Greulich-Pyle } \\
\text { standard } 19 \text { years }\end{array}$ & $\begin{array}{l}87.5 \% \text { of individuals will be more than } 17 \\
\text { years } 6 \text { months }\end{array}$ & $\begin{array}{l}97.5 \% \text { of individuals will be more than } 16 \\
\text { years } 3 \text { months }\end{array}$ & $23 \%$ \\
\hline & Combined & $\begin{array}{l}75 \% \text { of individuals will be between } 16 \text { years } \\
8 \text { months and } 19 \text { years } 7 \text { months }\end{array}$ & $\begin{array}{l}95 \% \text { of individuals will be between } 15 \text { years } \\
6 \text { months and } 20 \text { years } 3 \text { months }\end{array}$ & $45 \%$ \\
\hline
\end{tabular}

